\title{
Characterizing Student Participation in an ISLE Physics Class
}

\author{
David T. Brookes, Binod Nainabasti and Yuehai Yang \\ Department of Physics, Florida International University, 11200 S.W. $8^{\text {th }}$ St., CP 204, Miami, FL 33199
}

\begin{abstract}
In the participationist perspective, learning is viewed in terms of how students transform their participation. However, many of the seminal papers discussing the participationist framework are vague on specific details about what student participation really looks like on a more fine-grained scale. As part of a larger project to understand the role of student participation in learning, we are trying to characterize the ways in which physics students participate in group activities and discussions while they are constructing new knowledge. The context for our study is a student-centered introductory calculus-based physics class structured around the Investigative Science Learning Environment (ISLE) philosophy. In this paper we will discuss some of the patterns of participation we have found and some of the challenges we have encountered in trying to code and quantify student participation from analyzing video data.
\end{abstract}

Keywords: Physics education, participation.

PACS: 01.40.Fk, 01.40.Ha

\section{INTRODUCTION}

Our Investigative Science Learning Environment (ISLE) physics classroom is centered around the idea that students must transform the way that they participate in classroom activities. At the core of the ISLE philosophy is the idea that, in order to learn physics, students need to think and behave like practicing physicists [1]. In order for students to become knowers and doers of physics, they need to transform the way they participate in class discussions. From our observations, when students enter our classroom their dominant prior experiences of school learning involve an instructor and/or textbook providing them with the information that they are expected to learn. Students see themselves as recipients of knowledge, rather than generators of knowledge. They are thrown into a highly collaborative classroom environment where they are expected to learn physics from each other and from external resources of their own choosing, with fading support from the instructor as the semester progresses. They are confronted with a new set of expectations about how they should behave, what they are expected to do, and how they engage in the classroom, with the instructor, and with external resources such as textbooks and youtube videos. In previous work we have documented how this transformation process takes place using pre/post student interviews and CLASS data [2].

However we are still missing an important piece of the puzzle: We would like to gain a much finer- grained understanding of what goes on when students collaborate intensively with each other to learn physics. This in turn will allow us to answer interesting research questions such as: Does their collaboration shift as the semester progresses? Does the way in which they interact affect their learning and understanding of the material? How do some students become marginalized or other students come to dominate in collaborative discussion? Our ongoing project is to analyze video data of students working together while they learn physics. We would like to identify specific ways in which students participate in discussions and understand how their actions either support or hinder their learning. The goal of this paper is to establish a framework for analyzing student participation and a reliable way to code their talk and actions. If we can establish a framework and coding scheme, we will then be able to answer bigger research questions such as understanding how students' participation changes over the course of a semester.

\section{THEORETICAL FRAMEWORK}

In this paper we will model the participants in our classroom (students and instructors) as members of a community of learners working together towards shared learning goals [3]. This viewpoint is part of a larger set of models that fall under the label of the participationist framework. Students transform their participation as members of a community of practice by beginning their participation as legitimate 
peripheral participants, gradually moving to becoming central participants [4].

In order to understand how students transform their participation, we want to examine student participation on a fine-grained level. In our first attempts to characterize what students do in collaborative discussions, we observed that students ask questions, they explain things to each other, they present tentative ideas to the group for consideration, they discuss what they are "supposed to be doing," or what the purpose of a particular activity might be, and sometimes they simply watch and listen to more active group members. However it proved difficult for us to reliably distinguish between the different categories of statements that students make. As we analyzed our video data, we came to realize that every studentstudent or student-instructor interaction involves some degree of inequality. The degree of inequality will determine how much access less confident students have to critical semiotic resources in the classroom [5]. For example, afraid of showing her lack of understanding, a student may choose to watch other group members construct a ray diagram on a whiteboard as opposed to actively helping the group to draw the diagram. In Esmonde's research [5], she suggests that students position themselves in every interaction and this positioning in turn can create space or reduce the space for others to participate in meaningful ways. She identified four categories of positioning: "Expert," "novice," "inbetween," and "facilitator." We used these four categories as a starting point for developing our coding scheme.

\section{METHODS AND PARTICIPANTS}

Our participants are a group of 29 students enrolled in a studio-based introductory physics class based on the ISLE philosophy. The class is arranged in such a way that there are 5 tables in the room, each seating two groups of 3 students. We video-taped students at 4 of the 5 tables covering a total of 23 students, while they worked on a particular exercise in which they had to construct ray diagrams to locate the position of the image formed by a concave mirror. They had to draw ray diagrams for different positions of the object. 1) Outside of $\mathrm{C}$, the center of curvature, 2) between the focus $\mathrm{F}$ and $\mathrm{C}$, and 3 ) inside $\mathrm{F}$. When we coded their interactions, we only examined the time interval during which students seated at each table worked on the ray diagrams activity.

In order to code students' interactions we used a time-lining technique used by Karelina and Etkina [6]. We broke each video up into 15-second segments and made a judgment about how each student in that video was positioned in that particular 15-second interval.
Our judgments were based on both verbal and nonverbal communication such as body positioning and gaze. We found that how students positioned themselves during interactions was rather fluid. As a result, 30 second intervals proved to be too long since a student might adopt multiple positions in a 30 second interval. Shorter time intervals than 15 seconds became prohibitively difficult to code and caused us to lose context. We found 15 second intervals to be ideal.

We began with Esmonde's four categories [5] but quickly found that we needed to expand the number of categories in order to capture the nuances of the interactions endemic to our classroom. We developed the categories recursively. Through repeated coding and group discussion we refined the category descriptions and identified exemplars of interactions that belonged to each category. Once our categories had been established, we coded video samples with three independent coders. We were able to achieve $69 \%$ agreement before discussion and over $95 \%$ agreement after discussion.

\section{DEVELOPING THE CATEGORIES}

TABLE 1. Positioning categories in student interactions.

\begin{tabular}{|c|c|c|}
\hline \multicolumn{2}{|r|}{ Category } & Description \\
\hline 1 & Expert & $\begin{array}{l}\text { Presents information or controls } \\
\text { semiotic resources with confidence }\end{array}$ \\
\hline 2 & Intermediate & Softens expert tone by using \\
\hline & Expert & $\begin{array}{l}\text { "hedging" words such as "I think..." } \\
\text { or "I guess, maybe..." }\end{array}$ \\
\hline 3 & $\begin{array}{l}\text { Intermediate } \\
\text { Novice }\end{array}$ & $\begin{array}{l}\text { Seeking confirmation for tentative } \\
\text { explanation or asking high-level } \\
\text { "why" questions. }\end{array}$ \\
\hline 4 & Novice & $\begin{array}{l}\text { Asking lower-level questions like } \\
\text { "How do I do this?" or expressing } \\
\text { ignorance: "I don't understand..." }\end{array}$ \\
\hline 5 & $\begin{array}{l}\text { Listening } \\
\text { Observing }\end{array}$ & $\begin{array}{l}\text { Student does not speak, but shows } \\
\text { clear evidence that they are paying } \\
\text { attention in a collaborative activity. }\end{array}$ \\
\hline 6 & Facilitating & $\begin{array}{l}\text { Metacognitive discussion about the } \\
\text { purpose of what they are doing, or } \\
\text { planning future actions. }\end{array}$ \\
\hline 7 & $\begin{array}{l}\text { Interacting } \\
\text { inaudible }\end{array}$ & $\begin{array}{l}\text { Cases where it is clear that someone } \\
\text { is talking to someone else, but the } \\
\text { conversation is inaudible. }\end{array}$ \\
\hline 8 & $\begin{array}{l}\text { Interacting } \\
\text { with instructor }\end{array}$ & $\begin{array}{l}\text { Same categories } 1-5 \text {, but coded as } \\
8.1-8.5 \text {, indicating that the } \\
\text { conversation is taking place with an } \\
\text { instructor as opposed to a fellow } \\
\text { student. }\end{array}$ \\
\hline 9 & $\begin{array}{l}\text { Working alone } \\
\text { or off-topic }\end{array}$ & $\begin{array}{l}\text { Cases where students work alone or } \\
\text { are engaged in off-topic } \\
\text { conversation. }\end{array}$ \\
\hline
\end{tabular}

From examining our data we realized that in order to capture the different ways in which students positioned themselves in discussions, we had to expand Esmonde's categories of expertise from 4 to 6 . 
First, we broke up the "in-between" category into two subcategories: "intermediate novices," and "intermediate experts." Second, we added a category of "listening/observing" since there were situations where we could deduce from body positioning and eye contact that a student was listening to other students' conversation. However, because of their lack of interaction, it was unclear how they were positioning themselves. The complete set of categories that we devised for coding is shown in Table 1 with short descriptions that explain the category. After that we will show examples of discourse belonging to each category and discuss patterns that emerged.

\section{Elaborating the Categories}

\section{Expert}

We came up with the following set of exemplars of activities or utterances that position the participant as an expert:

1) Confidently doing something (e.g. drawing a ray diagram) or confidently producing an explanation. In the example below Simon is positioned as an expert:

Simon: Anything that passes through... anything that goes parallel towards the mirror bounces off and goes through the focal point. Anything that goes through the focal point bounces off and goes parallel.

2) Providing confirmation or directly answering a question with confidence.

Denise: Oh, okay...this straight like that?

And then this, like this, right?

Gloria: Exactly.

3) Confidently denying an idea or correcting someone else. In the following example, Jason simply rebuffs Nate's claim:

Nate: So everything your eye sees is upside down, right? Doesn't that make it a real image?

Jason: No, wrong. It's virtual when you're here.

4) Exhibiting a lack of patience to listen, cutting another speaker off, or fighting for authority.

Rob: See, I said that, you, you, you no listen. Jason: You no listen.

\section{Intermediate Expert}

1) Sentence completion. In the example below Paul is listening to Gloria's explanation (we coded her position as expert), but is not content to sit back and listen. Instead he appears to want to actively engage in co-constructing an explanation.
Gloria: and the one that goes parallel [goes

back]

Paul: [goes back] to the focus.

The square brackets indicate that their "goes back" overlap each other.

2) Offering a tentative explanation or softening an explanation by adding "hedging" words or by requesting confirmation. An expert can appear to "soften" his/her position by adding hedging words or phrases such as "I think..." or "Maybe..." Similarly an explanation can sound more tentative if it is followed by a sentence like "What do you think?" In the following example Gloria hedges by starting her sentence with "I guess you could..."

Paul: Oh, it meets at the same point... so you can do either one.

Gloria: Um, I guess you could do either one, but it's safer to do the one that goes through

the focus and then parallel, and then parallel and goes through the focus.

3) Socratic questioning. Although relatively rare, we included this in the intermediate expert category. An expert can soften his/her position by creating space for the novice to provide an explanation and move into the intermediate novice category (see below).

\section{Intermediate Novice}

In coming up with the category of intermediate novice, we were motivated by observing from our data that there were two clear categories of novice participation. Novices appeared to function as passive recipients of information, but intermediate novices were able to provide information back to the expert or intermediate expert. They were not content to passively listen, but tried to demonstrate some level of competence while seeking help or confirmation from someone more knowledgeable. The following are exemplars of the intermediate novice category:

1) Seeking confirmation of the answer to a problem.

Denise: Okay, so, this first ray hits the mirror

straight and then goes back through the

focus, right?

Paul: Yes ma'am.

In this example Denise is doing more than simply asking for information. She is actively engaged in drawing the ray diagram while asking Paul for confirmatory support.

We also encountered cases where the student in question did not speak at all, but was executing a drawing under the guidance of an expert. We categorized such instances in the intermediate novice category.

2) Seeking deeper explanation or understanding. We decided that we could reliably identify questions 
that were asked by a student to reach a deeper understanding of the topic. These questions often began with "Why...?" or "What is the purpose of...?"

3) Responding to questions in the context of a Socratic dialogue. The Socratic dialogue naturally opens up a space for a novice to move into the intermediate novice category by constructing explanations guided by an expert or an instructor.

4) Explaining back, rephrasing expert's explanation for confirmation. For example Claire responds to Simon's explanation about where the principle rays travel:

Claire: Ya, I'm starting to understand what

you are saying. The object hits the mirror,

then it goes back through the focal point.

Then ... this one hits the [inaudible] and goes

back through the focal point.

\section{Novice}

1) Agreeing with an explanation without providing any other information.

2) Asking a question that is procedural in nature or very limited in scope. For example:

Denise: Oh wait a minute. How would you do this one?

3) Directly expressing a novice position. Students frequently express their ignorance as in the following example where Ian is asking for help from Paul:

Ian: I don't know how I did this one.

\section{Listening or Observing}

We found this to be an extremely difficult category to code reliably until we came up with the following stringent conditions: We agreed that clear evidence of listening must involve one or more of the following: Making clear eye-contact, leaning forward, switching eye contact between speakers, raising one's head, or being directly spoken to by another.

\section{Facilitating}

Facilitation turned out to be a rather broad category with the following exemplars.

1) Suggesting a way to figure out a problem. For example, "This is similar to the mirror problem we did in homework."

2) Posing general question to the group. For example:

Clive: So, what do we know about that?

3) Rephrasing a question or an answer for other students who didn't understand.

4) Encouraging group members to solve a problem. For example:
Denise: Practice makes perfect.

5) Offering positive support to others. For example,

Simon: "That is a good question"

6) Discussing the purpose of a task. For example, in responding to Clive's question about why they were doing the ray tracing activity, Kevin responds, "we have to refresh our memory on ray tracing."

\section{DISCUSSION}

While probably not exhaustive, our positioning categories in interactions were able to capture the majority of students' utterances and actions while they were engaged in collaborative activities. In summary, we frequently found that positioning is a give and take between the participants in the interaction. For example, an expert's position can depend on how he choses to talk about his/her ideas, but (s)he can also be placed in that position by others choosing to position themselves as novices. In the future we will be able to use this coding scheme to study how students transform their participation roles in group activities and discussions as they learn how to interact and collaborate effectively with each other in a student centered physics course. We also aim to study how this transformation will, in turn, affect their learning.

\section{ACKNOWLEDGMENTS}

The authors would like to acknowledge the Physics Education Research Group at FIU. This research was supported in part by NSF Grant \#0802184.

\section{REFERENCES}

1. E. Etkina, and A. Van Heuvelen, "Investigative Science Learning Environment-A Science Process Approach to Learning Physics," in Research-Based Reform of University Physics, edited by E. F. Redish, and P. J. Cooney, 2007, vol. 1.

2. D. T. Brookes, and Y. Lin, "Designing a physics learning environment: A holistic approach," in Proceedings of the 2011 Physics Education Research Conference, edited by N. S. Rebello, P. V. Engelhardt, and C. Singh, AIP, Melville, NY, 2012, pp. $131-134$.

3. B. Rogoff, E. Matusov, and C. White, "Models of Teaching and Learning: Participation in a Community of Learners," in Handbook of Education and Human Development, edited by D. R. Olson, and N. Torrance, Blackwell, Oxford, UK, 1996, chap. 18, pp. 388-414.

4. J. Lave, and E. Wenger, Situated Learning: Legitimate Peripheral Participation, Cambridge University Press, Cambridge, U.K., 1991.

5. I. Esmonde, J. Learn. Sci. 18, 247-284 (2009).

6. A. Karelina and E. Etkina, Phys. Rev. ST Phys. Educ. Res. 3, 020106 (2007). 